\title{
Clinicopathological Factors and Gastric Cancer Prognosis in the Iranian Population: a Meta-analysis
}

\author{
Mohammad Hossein Somi ${ }^{1}$, Morteza Ghojazadeh ${ }^{1}$, Masood Bagheri ${ }^{2 *}$, Taraneh \\ Tahamtani $^{3}$
}

\begin{abstract}
Background: Gastric cancer is the most common cancer in the Iranian population. The aim of this study was to determine the effect of clinicopathological factors on prognosis by meta-analysis. Materials and Methods: A literature search was conducted using MEDLINE, EMBASE and Cochrane library and extensive literature search using the Persian databases until February 2011. Prospective follow up studies with multivariate analysis of overall survival of the patients with gastric cancer were included in this review. The data were analyzed by CMA.2. Publication bias are checked by funnel plot and data are shown as Forest plots. Results: From a total of 63 articles, 14 retrospective studies which examined 5 prognostic factors and involving 10,500 patients were included. Tumor size $(>35 \mathrm{~mm})$ was the main significant factor predicting an unfavorable prognosis for the patients with gastric cancer $(R R=1.829, p<0.001)$ followed by presence of distant metastases $(R R=1.607, p<0.001)$, poor differentiation $(R R=1.408, p<0.001)$ and male sex $(R R=1.194, p<0.001)$. Lymph node metastases $(R R=1.058$, $p=0.698)$ and moderate differentiation $(R R=0.836, p=0.043)$ were not statistically significant as prognostic factors. Conclusions: This meta-analysis suggests that tumor size $>35 \mathrm{~mm}$, poor differentiation, presence of distant metastasis and male gender are strongly associated with a poor prognosis in Iranian patients with gastric cancer.
\end{abstract}

Keywords: Gastric cancer - prognosis - meta-analysis - Iran - tumour size - distant metastases - gender

Asian Pac J Cancer Prev, 16 (3), 853-857

\section{Introduction}

According to the world estimate of cancer incidence by the International Agency for Research on Cancer, gastric cancer is still one of the most common cancers in the world. It comprises $9 \%$ of all cancers as the fourth most prevalentafter cancer of the lung, breast, and colorectal, and is the second most common cancer related cause of death ( $10 \%$ of all cancer deaths) after lung cancer (Center for Disease Control and Prevention, 2013).

Mortality rates due to malignancies have remained as a major health problem all around the world (Ferlay et al., 2013) as well as in Iran (Movahedi et al., 2009). Epidemiologic studies in Iran show that the incidence of gastric cancer estimated to be as high as 26.1 men and in women is about 11.1 per 100,000 (Sadighi et al., 2005; Somi et al., 2008). This cancer is very lethal mostly because most patients are at advanced stage at the time of diagnosis (Sadighi et al., 2005; Eskandar et al., 2006).

Prevalence of gastric cancer is not identical all around Iran (Eskandar et al., 2006; Hossein et al., 2006). There are reports on prognostic factors and survival rate of patients with gastric cancer from different regions of Iran which have some differences as well (Moghimi-Dehkordi et al., 2009; Movahedi et al., 2009). Several variables representing pathological, clinical and therapeutic characteristics have already been studied in numerous retrospective reports as an attempt to identify prognostic indicators in patients with gastric cancer. Such studies recently aim to define high-risk patients who may benefit from adjuvant therapies (5) to organize more appropriate treatment plans and reaching better outcomes. Studies differ in methodology and design indeed and significance of the prognostic factors are not the same in all of studies. Many of these studies have indicated that the size, grading and differentiation of the tumor, presence of distant metastases and lymph node involvement are the most important prognostic factors in gastric carcinoma while the relationship between prognosis and gender of patients is still controversial (Maruyama, 1987).

This study aimed to reach a conclusion on prognostic factors of gastric cancer in Iranian patients. To compare this clinicopathological factors that affect the overall survival of patients with gastric cancer in Iranian patients, all of the retrospective studies which examined 5 prognostic factors were analyzed.

${ }^{1}$ Liver and Gastrointestinal Diseases Research Center, ${ }^{2}$ Students Research Committee, Tabriz University of Medical Sciences, East Azerbaijan, Tabriz, ${ }^{3}$ Continuing Medical Education, Tehran University of Medical Sciences, Tehran, Iran *For correspondence: bagheri_m1368@yahoo.com 


\section{Materials and Methods}

We used a protocol according to guidelines for systematic reviews in health care (Egger and Smith, 2001) to carry out this systematic review. A comprehensive literature search was conducted using MEDLINE, EMBASE and Cochrane library on published articles up to February 2011 in the following languages: English, Persian, German, French, Arabic and Turkish. Prospective follow up studies with multivariate analysis on overall survival of the patients with gastric cancer were included in this meta-analysis based on the medical subject heading $(\mathrm{MeSH})$ terms for following search strategy:

"(( "prognos\$” or "prognosis" or "prognostic"). af.) AND ((exp stomach neoplasms/) OR (("stomach neoplasms" or "gastric cancer" or "stomach cancer" or "gastric carcinoma").tw,ti.)) AND (iran.mp. [mp=ti, ot, ab, tx, ct, sh, kw, ps, sj, do, dv, po, go, rs, nm, hw, an, ui]))"

Additionally, extensive literature search using the Persian databases \{IranMedex (www.iranmedex.com), Scientific information database (www.sid.ir), MagIran ( www.magirna.com )\} and a hand search was performed of following journals: Govaresh (www.govaresh.org), Middle East Journal of Cancer (mejc.sums.ac.ir), Achives of Iranian Medicine (www.aimjournal.ir), Iranian Journal for cancer prevention (http://journals.sbmu.ac.ir/cp ). In addition, the cited references in published articles were also manually reviewed for relevant results.

The systematic literature search yielded 63 articles and full text versions of all were obtained. Three independent investigators extracted data to rule out potential bias or errors. The agreement rate to the quality evaluation of each article between the reviewers was $88.6 \%$ and discrepancies were resolved by consensus or discussed with a fourth investigator if necessary. All of these steps are described in Figure 1.

A total of fourteen retrospective studies that contained inclusion criteria were included which examined 5 prognostic factors (tumor size, distant metastases, differentiation, sex and Lymph node metastases) including 10500 patients (Table 1). The following information was collected from each study: the name of the first author, the year of publication, the city or academic center, the number of subjects, effect size and hazard ratio with $95 \%$ confidence interval, etc.

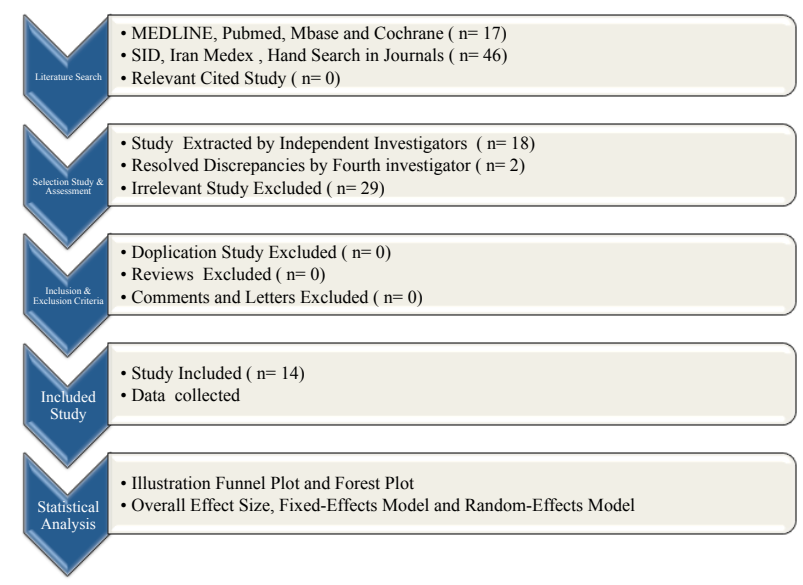

Figure 1. Methodology of the Study
Data were analyzed by CMA.2 software. We categorized the included studies according to the prognostic factors (tumor size, distant metastases, differentiation, sex and Lymph node metastases). The relationship between each of the clinicopathologic factors and prognosis of gastric cancer was assessed by the effect size with $95 \%$ confidence interval $(\mathrm{CI})$. The fixed-effects model and random-effects model were used to estimate the overall effect size. In addition, the sample sizes and effect size of each article were illustrated using funnel plot to assess publication bias.

\section{Results}

The systematic literature search yielded 63 articles. The full text versions of all of them were obtained and 14 articles were selected on the basis of the described selection criteria by three independent investigators. The agreement rate to the quality evaluation of each article between the reviewers was $88.6 \%$ and discrepancies were resolved by consensus or discussed with a fourth investigator if necessary.

A total of fourteen retrospective studies examined at least of the mentioned prognostic factors and involved 10,500 patients. We categorized the included studies according to the prognostic factors (tumor size, distant metastases, differentiation, sex and lymph node metastases) and data was collected from each study (Figure 2).

\section{Tumor size}

Tumor size $(>35 \mathrm{~mm})$ was the main significant factor predicting an unfavorable prognosis for the patients with gastric cancer $(\mathrm{RR}=1.829$; $\mathrm{CI}=1.439-2.325, \mathrm{p}<0.001$, Figure 3). The highest hazard ratio for the relationship between tumor size and prognosis of gastric cancer is shown in a study by Baghestani et al in 2009 ( $R R=2.29$, $\mathrm{p}<0.023)$ and the lowest is shown in the study by Pourhoseingholi et al in 2007 ( $R R=0.5, p=0.167)$.

\section{Presence of distant metastases}

The presence ( $v s$ absence) of distant metastases was associated with poorer overall survival $(\mathrm{RR}=1.607$; $\mathrm{CI}=1.431-1.801, \mathrm{p}<0.001$, Figure 4). The highest hazard ratio for the relationship between presence of distant metastases and prognosis of gastric cancer is shown in

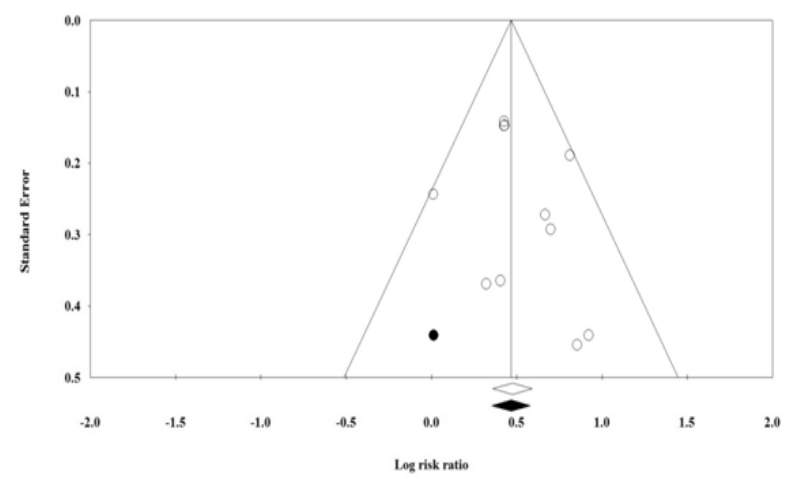

Figure 2. Funnel Plot for Sample Size and Effect Size of Studies Examining Distant Metastases and Prognosis of Gastric Cancer

854 Asian Pacific Journal of Cancer Prevention, Vol 16, 2015 
Table 1. Characteristics of the Selected Studies for Meta-analysis

\begin{tabular}{|c|c|c|c|c|}
\hline First author & University & Date & Assessed factor(s) & $\begin{array}{l}\text { Hazard Ratio }(95 \% \mathrm{CI}) \\
\text { respectively }\end{array}$ \\
\hline Khedmat et al., 2011 & Baqyiatollah & 2011 & Gender & $1.50(1.00-2.10)$ \\
\hline $\begin{array}{l}\text { Pourhoseingholi et al., } \\
2011\end{array}$ & Shaheedbeheshti & 2011 & $\begin{array}{l}\text { Tumor size, Metastasis, Gender, } \\
\text { Lymph node metastasis, } \\
\text { Differentiation }\end{array}$ & $\begin{array}{l}1.66(1.11-2.56), 1.01(0.62-1.61), \\
1.04(0.80-1.32), 1.02(0.72-1.45), \\
1.50(1.01-2.23)\end{array}$ \\
\hline $\begin{array}{l}\text { Baghestani et al., } \\
2010 \mathrm{~b}\end{array}$ & Tarbiat Modares & 2010 & $\begin{array}{l}\text { Tumor size, Metastasis, Gender, } \\
\text { Lymph node metastasis, } \\
\text { Differentiation }\end{array}$ & $\begin{array}{l}2.24(1.14-4.38), 2.51(1.06-5.97), \\
1.77(0.94-3.35), 2.19(0.68-7.02), \\
0.51(0.27-0.97)\end{array}$ \\
\hline $\begin{array}{l}\text { Moghimi-Dehkordi et } \\
\text { al., } 2009\end{array}$ & Shaheedbeheshti & 2009 & Metastasis, Differentiation & $\begin{array}{l}1.533(1.141-2.046), 1.547(1.079- \\
2.217)\end{array}$ \\
\hline $\begin{array}{l}\text { Baghestani et al., } \\
2010 \mathrm{a}\end{array}$ & Tarbiat Modares & 2009 & Tumor size, Metastasis & $2.33(1.268-4.55), 1.5(0.72-3.01)$ \\
\hline Movahedi et al., 2009 & Shaheedbeheshti & 2009 & Gender & $1.21(1.10-1.32)$ \\
\hline $\begin{array}{l}\text { Moghimi-Dehkordi } \\
\text { 2009) }\end{array}$ & Shaheedbeheshti & 2009 & Metastasis & $2.251(1.555-3.259)$ \\
\hline Rajaei Fard et al., 2009 & Shiraz & 2009 & Metastasis, Differentiation & $1.53(1.16-2.02), 1.45(1.10-1.91)$ \\
\hline Baghestani et al., 2009 & Tarbiat Modares & 2009 & $\begin{array}{l}\text { Tumor size, Metastasis, Lymph } \\
\text { node metastasis, Differentiation }\end{array}$ & $\begin{array}{l}2.29(1.16-4.83), 2.35(0.93- \\
5.52), 2.18(0.66-1.31), 0.52(0.266- \\
1.015)\end{array}$ \\
\hline $\begin{array}{l}\text { Moghimi-Dehkordi et } \\
\text { al., } 2008\end{array}$ & Shaheedbeheshti & 2008 & Metastasis, Differentiation & $1.53(1.16-2.02), 1.45(1.10-1.91)$ \\
\hline $\begin{array}{l}\text { Pourhoseingholi et al., } \\
\text { 2009a }\end{array}$ & Shaheedbeheshti & 2008 & Tumor size, Metastasis, Gender & $\begin{array}{l}2.04(1.22-3.33), 2.01(1.13- \\
3.56), 1.33(0.822 .17)\end{array}$ \\
\hline $\begin{array}{l}\text { Pourhoseingholi et al., } \\
\text { 2009b }\end{array}$ & Shaheedbeheshti & 2009 & $\begin{array}{l}\text { Tumor size, Metastasis, Gender, } \\
\text { Lymph node metastasis, } \\
\text { Differentiation }\end{array}$ & $\begin{array}{l}0.50(0.19-1.34), 1.38(0.67-2.85), 1.03 \\
(0.62-1.69), 2.06(0.92-4.60), 1.00 \\
(0.56-1.78)\end{array}$ \\
\hline $\begin{array}{l}\text { Moghimi-Dehkordi et } \\
\text { al., } 2011\end{array}$ & Shaheedbeheshti & 2007 & Metastasis, Differentiation & $1.53(1.15-2.05), 1.56(1.08-1.22)$ \\
\hline Zeraati et al., 2005 & Tehran & 2006 & $\begin{array}{l}\text { Metastasis, Lymph node } \\
\text { metastasis }\end{array}$ & $\begin{array}{l}1.946(1.141-3.320), 1.787(1.188- \\
2.686)\end{array}$ \\
\hline
\end{tabular}

a study by Baghestani et al in $2010(\mathrm{RR}=2.51, \mathrm{p}=0.037)$ and the lowest is shown in a study by Pourhoseingholi et al in $2010(\mathrm{RR}=1.01, \mathrm{p}=0.967)$.

\section{Lymph node metastases}

The presence ( $v s$ the absence) of lymph node metastases was not statistically significant in prognosis of patients with gastric cancer $(R R=1.058, p=0.698)$.

\section{Differentiation}

Although moderate differentiation was not statistically significant in prognosis of patients with gastric cancer ( $R R=0.836, p=0.43)$ but poorly differentiation was predicting an unfavorable prognosis in the patients $(\mathrm{RR}=1.408 ; \mathrm{CI}=1.229-1.613, \mathrm{p}<0.001$, Figure 5). The highest hazard ratio was shown in a study by Moghimidehkordi et al in $2009(\mathrm{RR}=1.56, \mathrm{p}=0.016)$ and the lowest in Baghestani et al in $2010(\mathrm{RR}=0.68, \mathrm{p}=0.262)$. Moderate differentiation ( $R R=0.836, p=0.043$ ) was not statistically significant as prognostic factor.

\section{Gender}

Male gender ( $v s$ female) was associated with poorer overall survival in patients with gastric cancer $(R R=1.194$

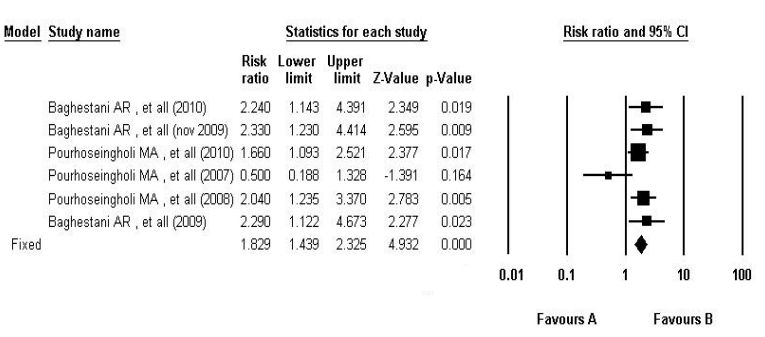

Figure 3. Forest Plot for Association Between Tumor Size $(>35 \mathrm{~mm})$ and Prognosis of Gastric Cancer

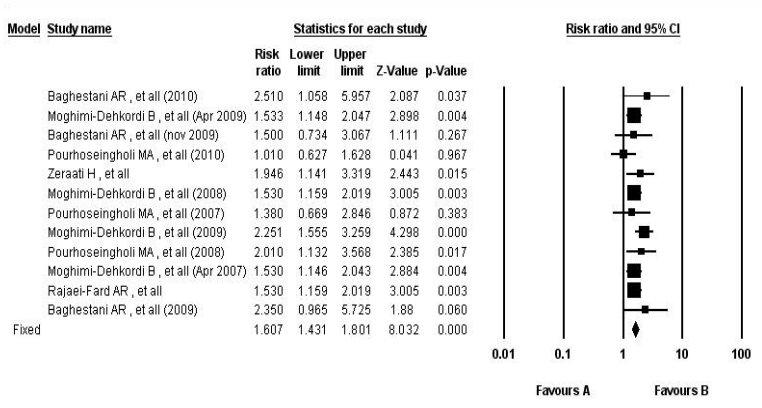

Figure 4. Forest Plot for Association Between Presence vs Absence of distant metastasis and Prognosis of Gastric Cancer 
Meta Analysis

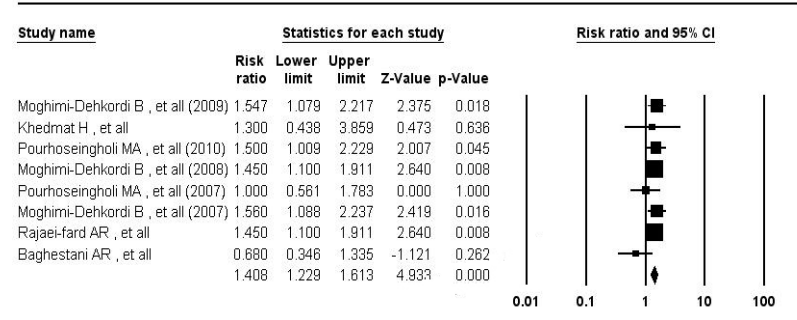

Figure 5. Forest Plot for Association Between Poor Differentiation and Prognosis of Gastric Cancer

(CI=1.104-1.291, $\mathrm{p}<0.001)$.

Forest plots are illustrated for tumor size, presence of distant metastases and differentiation as main factors in prognosis of gastric cancer patients in order to have a better understanding of the influence of the included studies.

\section{Discussion}

Numerous prognostic factors for survival of patients with gastric cancer are introduced based on readily available data and provide a good but not perfect estimate survival of these patients. The aim of this study was to determine independent prognostic factors for survival of patients with gastric cancer in Iran based on the research in this population. In this study tumor size $(>35 \mathrm{~mm})$, presence of distant metastases and poorly differentiation were introduced as main factors affecting prognosis of gastric cancer in Iranian patients.

While several treatment-related and patient- related factors may influence the survival, size of the tumor has been introduced as a simple and independent factor predicting the prognosis of gastric cancer. Large size of the tumor has also been noticed to be related with undifferentiation, tumor and lymph node invasion and peritoneal recurrence in the future (Saito et al., 2006; Wang et al., 2008). Gross appearance and size of the tumor has also been introduced as an indicator for deciding the extend of lymph node resection even in early stages of gastric cancer (Tsujitani et al., 1999) and leads to modification of curative and palliative interventions ( $\mathrm{Li}$ et al., 2009). However results of these studies differ in regard of the proposed threshold of tumor size; ranging between 35 to $100 \mathrm{~mm}$ and even up to $8 \mathrm{~cm}$ (Kunisaki et al., 2008). This difference could be a result of histopathology of the tumor or may be influenced by other factors affecting the survival like treatment methods. Further researches are needed to make a conclusion before performing recommendation of researchers to include the tumor size in staging system of gastric cancer (Kunisaki et al., 2008; Wang et al., 2008; Liu et al., 2009).

Results of the meta-analysis indicate that presence ( $v s$ absence) of distant metastases was associated with poorer overall survival in patients with gastric cancer. Distant metastasis has been introduced as the most important prognostic factor for a long time (Maruyama, 1978). This one variable may be of especial importance for patients who benefit from interventions and might be a fine indicator for any curative intervention as well as an indicator for relapse (Zare et al., 2013). Missing this factor would also result in failure to reach the best result. A study on a large series of patients emphasized the importance of investigation for metastasis especially in early gastric cancer (Gotoda et al., 2000). Presence of lymph node metastasis was not a prognostic factor in the reviewed reports. Previous reports indicate lymph node metastasis as a strong prognostic factor in gastric cancer of any size (Yokota et al., 2004; Shiraishi et al., 2007). This difference does not seem to be explained by ethnical differences or histopathology of tumors in our region. However this result may be a sign of missing the lymph node involvement or micro-invasion as a result of inadequate investigation or subject to type of surgery (total gastrectomy $v s$ subtotal) reported by other studies as well (Selcukbirici et al., 2013). Studies oppose justified lymph node dissection because of the possibility of lymph node metastasis, even with accurate knowledge of the small depth of gastric cancer invasion (Yokota et al., 2001). Thus this issue needs to be addressed in further studies.

The prognostic role of female gender for a better survival in patient with gastric cancer is compatible with previous reports. Better survival rates has been noticed for women in most of cancer sub sites including stomach (Micheli et al., 2009). These studies emphasize the role of biological factors and suggest that women might be intrinsically more vigorous than men in coping with cancer, the advantage that markedly declines as age progresses beyond menopause. Nevertheless programs for health education in our region might improve the results for men by providing educations on appropriate life style modifications for cancer risk-factor behaviors, screening, early detection, symptom recognition, help seeking and psychosocial adaptation (Nicholas, 2000).

Interest in molecular markers of prognosis in cancer patients has been growing recently. Some of these markers account for more than one clinical-pathological marker (e.g. both lymph node in involvement and level of differentiation) (Hsu et al., 2009) and therefore seem to be appropriate and valuable markers. These results could be more reliable when including tumor markers as well (Mittal et al., 2013). Available researches about clinic-pathological factors affecting the prognosis in Iran seem to be an adequate stand for further research in molecular field.

In conclusion, this meta-analysis suggests that tumor size, differentiation, distant metastasis and gender might significantly influence prognosis of Iranian patients with gastric cancer. Tumor size $>35 \mathrm{~mm}$, poor differentiation, presence of distant metastasis and male gender are associated with a poor prognosis. Along with early detection, life style modifications educations in general population especially men and targeted treatments for introduced factors might improve survival rate of the patients.

\section{Acknowledgements}

This study was supported by the Liver and Gastrointestinal Diseases Research Center, Tabriz University of Medical Sciences, Tabriz, Iran. 


\section{References}

Baghestani AR, Hajizadeh E, Fatemi SR (2009). Bayesian analysis for survival of patients with gastric cancer in Iran. Asian Pac J Cancer Prev, 10, 823-6.

Baghestani AR, Hajizadeh E, Fatemi SR (2010a). Application of Bayes method in determining of the risk factors on the survival rate of gastric cancer patients. Koomesh, 11, 129-32.

Baghestani AR, Hajizadeh E, Fatemi SR (2010b). Parametric model to analyse the survival of gastric cancer in the presence of interval censoring. Tumori, 96, 433-7.

Center for disease control and prevention (2013). National Cancer Registry and Report. (2 $2^{\text {nd }}$ ed.) Ministry of Health and Medical Education.

Egger M, Smith GD (2001). Principles and procedures for systematic reviews. Systematic Reviews in Health Care: Meta-analysis in Context. ( $2^{\text {nd }}$ ed.) London: BMJ.

Eskandar H, Hossein SS, Rahim M, et al (2006). Clinical profile of gastric cancer in Khuzestan, southwest of Iran. World $J$ Gastroenterol, 12, 4832-5.

Ferlay J, Soeriomataram I, Ervik M, et al (2013). GLOBOCAN 2012 v1.0, Cancer incidence and mortality worldwide: IARC cancerbase. Lyon: International Agency for resrach on cancer.

Gotoda T, Yanagisawa A, Sasako M, et al (2000). Incidence of lymph node metastasis from early gastric cancer: estimation with a large number of cases at two large centers. Gastric Cancer, 3, 219-25.

Hossein S M, Mirinezhad K, Farhang, S, et al (2006). Gastrointestinal cancer occurrence in East Azarbaijan: a five year study from North Western Iran. Asian Pac J Cancer Prev, 7, 309-12.

Hsu PI, Hsieh HL, Lee J, et al (2009). Loss of RUNX3 expression correlates with differentiation, nodal metastasis, and poor prognosis of gastric cancer. Ann Surg Oncol, 16, 1686-94.

Khedmat H, Panahian M, Mashahdian M, Rajabpour MV, Zendehdel K (2011). Prognostic factors and survival in stomach cancer-analysis of 15 years of data from a referral hospital in iran and evaluation of international variation. Onkologie, 34, 178-82.

Kunisaki C, Makino H, Takagawa R, et al (2008). Tumor diameter as a prognostic factor in patients with gastric cancer. Ann Surg Oncol, 15, 1959-67.

Li C, Oh S, Kim S, et al (2009). Risk factors of survival and surgical treatment for advanced gastric cancer with large tumor size. J Gastrointest Surg, 13, 881-5.

Liu X, Xu Y, Long Z, Zhu H, Wang Y (2009). Prognostic Significance of tumor size in T3 gastric cancer. Ann Surg Oncol, 16, 1875-82.

Maruyama K (1987a). The most important prognostic factors for gastric cancer patients: a study using univariate and multivariate analyses. Scand J Gastroenterology, 22, 63-8.

Micheli A, Ciampichini R, Oberaigner W, et al (2009). The advantage of women in cancer survival: An analysis of EUROCARE-4 data. Europ J Cancer, 45, 1017-27.

Mittal A, Gupta SP, Jhan DK, Sathian B, Poudel B (2013). Impact of various tumor markers in prognosis of gastric cancer. A hospital based study from the tertiary care hospital of Kathmandu valley. Asian Pac J Cancer Prev, 14, 1965-7.

Moghimi-Dehkordi B, Safaee A, Ghiasi S, Zali MR (2009a). Survival in gastric cancer patients: univariate and multivariate analysis. East Afr J Public Health, 6, 41-4.

Moghimi-Dehkordi B, Safaee A, Pourhoseingholi M A, et al (2008). Statistical comparison of survival models for analysis of cancer data. Asian Pac J Cancer Prev, 9, 417-20.

Moghimi-Dehkordi B, Safaee A, Tabei SZ (2009). A comparison between Cox proportional hazard models and logistic regression on prognostic factors in gastric cancer. East Afr J Public Health, 6, 20-2.

Moghimi-Dehkordi B, Safaee A, Zali MR (2009b). Comparison of colorectal and gastric cancer: survival and prognostic factors. Saudi J Gastroenterol, 15, 18-23.

Movahedi M, Afsharfard A, Moradi A, et al (2009). Survival rate of gastric cancer in Iran. J Res Med Sci, 14, 367-73.

Nicholas DR (2000). Men, Masculinity, and cancer: risk-factor behaviors, early detection, and psychosocial adaptation. $J$ American College Health, 49, 27-33.

Pourhoseingholi MA, Hajizadeh E, Abadi A, et al (2009a). Prognostic factors in gastric cancer using log-normal censored regression model. J Gorgan Uni Med Sci, 11, 45-50.

Pourhoseingholi MA, Moghimi-Dehkordi B, Safaee A, et al (2009b). Prognostic factors in gastric cancer using lognormal censored regression model. Indian J Med Res, 129, 262-7.

Pourhoseingholi MA, Pourhoseingholi A, Vahedi M, et al (2011). Alternatives for Cox regression model: using parametric models to analyze the survival of cancer patients. Iran $J$ Cancer Prev, 1, 1-9.

Rajaeefard A, Moghimi-Dehkordi B, Tabatabaee H, et al (2009). Applying parametric models for survival analysis of gastric cancer. FEYZ, 13, 83-8.

Sadighi S, Raafat J, Mohagheghi M, Meemary F (2005). Gastric carcinoma: 5 year experience of a single institute. Asian Pac J Cancer Prev, 6, 195-6.

Saito H, Osaki T, Murakami D, et al (2006). Macroscopic tumor size as a simple prognostic indicator in patients with gastric cancer. Am J Surg, 192, 296-300.

Selcukbiricik F, Tural D, Bilici A, et al (2013). Clinicopathological features and localization of gastric cancers and their effects on survival in Turkey. Asian Pac J Cancer Prev, 14, 553-6.

Shiraishi N, Sato K, Yasuda K, Inomata M, Kitano S (2007). Multivariate prognostic study on large gastric cancer.J Surg Oncol, 96, 14-8.

Somi MH, Farhang S, Mirinezhad SK, et al (2008). Cancer in East Azerbaijan, Iran: results of a population-based cancer registry. Asian Pac J Cancer Prev, 9, 327-30.

Tsujitani S, Oka S, Saito H, et al (1999). Less invasive surgery for early gastric cancer based on the low probability of lymph node metastasis. Surg, 125, 148-54.

Wang X, Wan F, Pan J, et al (2008). Tumor size: A nonneglectable independent prognostic factor for gastric cancer. J Surg Oncol, 97, 236-40.

Yokota T, Ishiyama S, Saito T, et al (2004). Lymph node metastasis as a significant prognostic factor in gastric cancer: a multiple logistic regression analysis. Scand $J$ Gastroenterol, 39, 380-4.

Yokota T, Saito T, Teshima S, et al (2001). Probability of lymph node metastasis in small gastric cancer tumor: is it an indication for limited surgery? Int Surg, 86, 206-9.

Zare A, Mahmoodi M, Mohammad K, et al (2013). Survival analysis of patients with gastric cancer undergoing surgery at the Iran Cancer Institute: a method based on multi-state models. Asian Pac J Cancer Prev, 14, 6369-73.

Zeraati H, Mahmoudi M, Kazemnejad A, Mohammad K (2005). Postoperative survival in gastric cancer patients and its associated factors: a method based on a non-homogenous semi-markovian process. Int J Cancer Res, 1, 87-93. 